\title{
Genetic Influence on Flower Bud Density in Peach and Nectarine Exceeds That of Environment
}

\author{
W.R. Okie \\ U.S. Department of Agriculture, Agricultural Research Service, 111 Dunbar \\ Road, Byron, GA 31008
}

\section{D.J. Werner}

Department of Horticultural Science, Box 7609, North Carolina State University, Raleigh, NC 27695-7609

Additional index words. Prunus persica, fruit breeding

\begin{abstract}
Spring frosts often kill all or a portion of the flowers on peach [Prunus persica $(\mathrm{L}$. Batsch] trees in the southeastern United States. Increased flower bud density increases the likelihood of sufficient flowers surviving to produce a crop. The effect of environment on flower bud density (buds/node) was studied using two locations over 3 years. Bud density of 25 peach and nectarine varieties grown in completely randomized designs was measured in Georgia and North Carolina. Genotypic variability was greater than location or year effects. Varieties selected for high bud density at one location can be expected to have high densities at other locations with similar chilling.
\end{abstract}

Several times in the last decade the southeastern U.S. peach crop has been severely reduced by spring frosts. Survival of peach flower buds and flowers in the spring is a function of bud preconditioning, minimum temperature, bud hardiness, time of bloom, number of flowers, and uniformity of bud development. The number of flower buds depends on the length of shoot growth, number of nodes per unit length, and number of flower buds per node (density). Shoot growth and bud differentiation are a function of genotype and the growing conditions of the tree the previous summer. Nodes on moderately vigorous shoots typically have a single vegetative bud flanked by a pair of flower buds. Some nodes will have only a single flower bud or vegetative bud, or no visible bud at all, particularly on the younger part of the shoot, which reduces the mean flower bud count per node for the entire shoot. Blake (1933b) developed a rating scheme for flower bud density ranging from class $1(\approx 1.3$ to $2.0 \mathrm{buds} / \mathrm{cm})$ to class $6(<0.3 \mathrm{buds} / \mathrm{cm})$ and rated 135 genotypes over 3 years (Blake, 1933a). Werner et al. (1988) reported mean bud densities ranging from 1.59 flower buds per node for 'Harko' to 0.35 for 'Late Gold' during 1986-87 in North Carolina. Both authors reported consistent results from year to year for a given variety. Perez-Gonzalez (1993) lists bud densities of 50 varieties rated in Italy and categorized them on the basis of the number of buds per node.

Received for publication 11 Dec. 1995. Accepted for publication 30 May 1996. The cost of publishing this paper was defrayed in part by the payment of page charges. Under postal regulations, this paper therefore must be hereby marked advertisement solely to indicate this fact.
Flower bud density is relatively easy to measure compared to other components contributing to bud survival. However, the relative contributions of genotype vs. environment on bud density are not known. A large genetic component would make selection for high bud density more effective. This study was designed to compare the effects of genotype and environment on the flower bud density of 25 peach and nectarine varieties.

\section{Materials and Methods}

We selected 25 peach and nectarine varieties from the United States and several foreign countries (Table 1) to obtain a wide range of flower bud densities. June-budded trees on Lovell rootstock were planted in Spring 1986 at sites in Byron, Ga. (Faceville fine sandy loam soil; lat. $32^{\circ} 40^{\prime} \mathrm{N}$, long. $83^{\circ} 44^{\prime} \mathrm{W}$ ), and Clayton, N.C. (Norfolk sandy loam; lat. $35^{\circ} 39^{\prime} \mathrm{N}$, long. $78^{\circ} 30^{\prime} \mathrm{W}$ ). Both sites annually average $>1100 \mathrm{~h}$ of chilling below $7{ }^{\circ} \mathrm{C}$. Pertinent weather data were obtained from nearby National Weather Service sites (Table 2). Each site consisted of a completely randomized design using 25 varieties and four single-tree replications. Trees were maintained according to commercial recommendations for the area. Sample shoots were removed before trees were pruned in the spring. Beginning in 1988, as bud swell occurred (making it easier to distinguish flower from vegetative buds), typical 1year-old shoots oriented at $45^{\circ}$ angles from vertical were selected from around the canopy, and 10 were removed from each tree. Length, number of visible nodes, and number of flower buds were determined for each shoot. Bud density (flower buds/node) and internode length (nodes/length) were calculated. Data were analyzed by correlation and analysis of variance (ANOVA) (SAS Institute, 1987) using years as a split plot in time. Varieties and locations were considered fixed effects. Variance components (Table 3) for genetic and environmental effects were calculated from the expected mean squares (EMS) (Schultz, 1955). Variance $\left(\mathrm{V}_{\mathrm{v}}\right)$ of a variety mean was estimated as $\mathrm{V}_{\mathrm{v}}=\delta_{\mathrm{r}(\mathrm{lv})}^{2} / \mathrm{rl}+\delta_{\mathrm{yv}}^{2} / \mathrm{y}+\delta_{\mathrm{yr}(\mathrm{lv})}^{2} / \mathrm{yrl}+$ $\delta_{\mathrm{s}(\mathrm{rlv})}^{2} / \mathrm{srl}+\delta^{2}{ }_{\mathrm{e}} / \mathrm{srly}$, where s, r, $1, \mathrm{y}$, and $\mathrm{v}$ represent the number of shoots, replications, locations, years, and varieties, respectively (Jones et al., 1960). Corresponding estimated variance components for replication $\left(\delta_{\mathrm{r}(\mathrm{lv})}^{2}\right)$, year $\times$ variety $\left(\delta_{\mathrm{yv}}^{2}\right)$, year $\times$ replication $\left(\delta_{\mathrm{yr}(\mathrm{lv})}^{2}\right)$, shoot $\left(\delta_{\mathrm{s}(\mathrm{rlv})}^{2}\right)$, and error $\left(\delta_{\mathrm{e}}^{2}\right)$ are from Table 3 . Broad sense heritability was estimated by the ratio of genetic variance : total phenotypic variance: $100 \times($ variety EMS $) /($ sum EMS $)$. Estimates of stability parameters were made following Fernandez (1991), as proposed by Shukla (1971) and Kang (1989).

\section{Results and Discussion}

Bud density ranged widely across varieties (Table 4). Most of the genotypes with higher densities were developed in regions with colder winter temperatures and more frequent spring frosts, in contrast to those from California. 'Agua 6-4', from the highlands of Mexico, where spring frosts occur regularly, has the highest bud density and probably has been selected over many generations for ability to crop reliably. Density values in this study correlated well with those from North Carolina in an earlier study (Werner et al., 1988) for the few varieties in common. Our density range was somewhat smaller than that reported by Blake (1933a), but he measured shorter shoots that may have had fewer budless nodes at the shoot apex. The only variety in common with Blake was 'Amarillo Tardio',

Table 1. Origin of peach and nectarine varieties used in bud density study in Georgia and North Carolina.

\begin{tabular}{ll}
\hline \hline Variety & \multicolumn{1}{c}{ Origin } \\
\hline Amarillo Tardio (PI55835?) & Spain \\
Agua 6-4 & Mexico \\
Bicentennial & Louisiana \\
Blake & New Jersey \\
Clayton & North Carolina \\
Cresthaven & Michigan \\
Eagle Beak (PI43289) & China \\
Flavortop & California \\
Hardired & \\
Junegold & Ontario \\
Majestic & California \\
Monroe & Louisiana \\
Norman & North Carolina \\
O'Henry & North Carolina \\
Parade & California \\
Pekin & California \\
Ta Tao \#6 (PI101668) & North Carolina \\
Redhaven & China \\
Redskin & Michigan \\
Reliance & Maryland \\
Sunhigh & New Hampshire \\
Sunprince & New Jersey \\
Surecrop & Georgia \\
Topaz & Louisiana \\
Winblo & Missouri \\
\hline Nectarine. & North Carolina \\
\hline
\end{tabular}

${ }^{\mathrm{z} N e c t a r i n e .}$ 
Table 2. Comparison of temperatures and rainfall pertinent to bud density, for Byron, Ga., and Clayton, N.C., for 1987-89. Data from the National Weather Service.

\begin{tabular}{|c|c|c|c|c|c|c|c|c|}
\hline \multirow[b]{2}{*}{ Year } & \multirow[b]{2}{*}{ Location } & \multicolumn{5}{|c|}{ Monthly mean } & \multirow{2}{*}{$\begin{array}{l}\text { Absolute } \\
\text { minimum }^{2}\end{array}$} & \multirow{2}{*}{$\begin{array}{c}\text { Annual } \\
\text { total }\end{array}$} \\
\hline & & May & June & July & August & January $^{z}$ & & \\
\hline \multicolumn{9}{|c|}{ Temperature $\left({ }^{\circ} \mathrm{C}\right)$} \\
\hline \multirow{2}{*}{1987} & Byron & 23 & 26 & 27 & 28 & 5 & -9 & --- \\
\hline & Clayton & 20 & 25 & 27 & 26 & 1 & -12 & --- \\
\hline \multirow[t]{2}{*}{1988} & Byron & 21 & 25 & 27 & 27 & 11 & -7 & --- \\
\hline & Clayton & 20 & 25 & 28 & 29 & 7 & -9 & --- \\
\hline \multirow{2}{*}{1989} & Byron & 21 & 26 & 26 & 26 & 11 & -13 & --- \\
\hline & Clayton & 18 & 26 & 25 & 26 & 10 & -12 & --- \\
\hline \multicolumn{9}{|c|}{ Rainfall (mm) } \\
\hline \multirow[t]{2}{*}{1987} & Byron & 110 & 90 & 60 & 120 & --- & --- & 1070 \\
\hline & Clayton & 50 & 30 & 50 & 90 & --- & --- & 1400 \\
\hline \multirow[t]{2}{*}{1988} & Byron & 60 & 30 & 110 & 150 & --- & --- & 1000 \\
\hline & Clayton & 60 & 90 & 110 & 100 & --- & -.- & 940 \\
\hline \multirow[t]{2}{*}{1989} & Byron & 100 & 130 & 180 & 40 & --- & --- & 1270 \\
\hline & Clavton & 140 & 180 & 120 & 120 & --- & -.- & 1440 \\
\hline
\end{tabular}

January of the following year; absolute minimum for winter beginning the year listed and ending the following year.

Table 3. Analysis of variance for flower bud density for 25 peach and nectarine varieties evaluated in Georgia and North Carolina 1988-90. Values based on four single-tree replications (Rep) per location and 10 shoots per tree per year. Variance components calculated using fixed effects model for variety and location. $\left(R^{2}=0.78 ; R^{2}\right.$ using tree means $=0.93$. $)$

\begin{tabular}{lrrrcr}
\hline \hline Source & \multicolumn{1}{c}{ df } & $\begin{array}{c}\text { Mean } \\
\text { square }\end{array}$ & F value & $P$ & $\begin{array}{c}\text { Variance } \\
\text { component }\end{array}$ \\
\hline Location $($ Loc $)$ & 1 & 19.40 & 17.16 & 0.0437 & 0.0064 \\
Variety $($ Var & 24 & 22.98 & 41.29 & 0.0001 & 0.0935 \\
Loc $\times$ Var & 24 & 0.64 & 1.24 & 0.2481 & 0.0011 \\
Rep $($ Loc $\times$ Var) & 150 & 0.24 & 1.38 & 0.0102 & 0.0023 \\
Shoot $($ Rep $\times$ Loc $\times$ Var) & 1800 & 0.07 & 1.04 & 0.1837 & 0.0009 \\
Year & 2 & 10.66 & 61.27 & 0.0001 & 0.0052 \\
Loc $\times$ Year & 2 & 1.03 & 5.95 & 0.0029 & 0.0009 \\
Var $\times$ Year & 48 & 0.48 & 2.77 & 0.0001 & 0.0038 \\
Loc $\times$ Var $\times$ Year & 48 & 0.44 & 2.52 & 0.0001 & 0.0066 \\
Year $\times$ Rep (Loc $\times$ Var) & 298 & 0.17 & 2.52 & 0.0001 & 0.0105 \\
Error & 3582 & 0.07 & & & 0.0689 \\
\hline
\end{tabular}

Table 4. Mean, standard error, and coefficient of variation (cv) for bud density, shoot length, nodes per shoot, and internode length for 25 peach and nectarine varieties grown in Georgia and North Carolina in 198890 (four replications per location). Replication means are calculated using 10 shoots. Correlations calculated using tree means for each year, location, and replication.

\begin{tabular}{|c|c|c|c|c|c|}
\hline \multirow[b]{2}{*}{ Variety } & \multicolumn{2}{|c|}{ Bud density ${ }^{2}$} & \multirow{2}{*}{$\begin{array}{l}\text { Shoot length } \\
(\mathrm{cm})\end{array}$} & \multirow{2}{*}{$\begin{array}{r}\text { Nodes } \\
\text { (no.) }\end{array}$} & \multirow{2}{*}{$\begin{array}{l}\text { Internode length } \\
\text { (cm) }\end{array}$} \\
\hline & Buds/node & $\mathrm{CV}$ & & & \\
\hline Agua 6-4 & $1.66 \pm 0.05$ & 16.2 & $50.4 \pm 1.4$ & $34.5 \pm 1.1$ & $1.48 \pm 0.04$ \\
\hline Eagle Beak & $1.46 \pm 0.05$ & 17.9 & $53.6 \pm 2.2$ & $27.6 \pm 1.2$ & $1.97 \pm 0.06$ \\
\hline Hardired & $1.13 \pm 0.03$ & 12.2 & $51.9 \pm 1.7$ & $26.0 \pm 0.8$ & $2.00 \pm 0.04$ \\
\hline Reliance & $1.10 \pm 0.05$ & 23.3 & $52.5 \pm 2.3$ & $27.2 \pm 1.0$ & $1.93 \pm 0.05$ \\
\hline Cresthaven & $1.03 \pm 0.04$ & 20.6 & $48.8 \pm 1.9$ & $27.7 \pm 1.0$ & $1.77 \pm 0.04$ \\
\hline Blake & $0.99 \pm 0.03$ & 15.1 & $45.2 \pm 2.0$ & $27.3 \pm 0.9$ & $1.65 \pm 0.03$ \\
\hline Amarillo Tardio & $0.88 \pm 0.03$ & 15.1 & $49.9 \pm 2.0$ & $27.0 \pm 0.8$ & $1.84 \pm 0.04$ \\
\hline Norman & $0.86 \pm 0.04$ & 22.5 & $49.8 \pm 1.7$ & $24.6 \pm 0.6$ & $2.03 \pm 0.05$ \\
\hline Surecrop & $0.85 \pm 0.03$ & 19.6 & $47.9 \pm 2.3$ & $27.2 \pm 0.8$ & $1.76 \pm 0.07$ \\
\hline Clayton & $0.85 \pm 0.04$ & 20.4 & $52.5 \pm 2.5$ & $27.7 \pm 0.9$ & $1.88 \pm 0.05$ \\
\hline Pekin & $0.83 \pm 0.04$ & 24.4 & $49.3 \pm 2.0$ & $26.8 \pm 0.7$ & $1.84 \pm 0.05$ \\
\hline Redhaven & $0.77 \pm 0.04$ & 24.6 & $51.4 \pm 2.3$ & $26.4 \pm 0.8$ & $1.94 \pm 0.05$ \\
\hline Junegold & $0.73 \pm 0.04$ & 25.6 & $47.3 \pm 2.2$ & $27.9 \pm 1.0$ & $1.70 \pm 0.06$ \\
\hline Redskin & $0.72 \pm 0.04$ & 24.0 & $53.2 \pm 2.4$ & $28.4 \pm 0.9$ & $1.87 \pm 0.05$ \\
\hline Bicentennial & $0.70 \pm 0.04$ & 30.5 & $51.5 \pm 2.1$ & $30.6 \pm 1.1$ & $1.69 \pm 0.05$ \\
\hline Sunprince & $0.70 \pm 0.04$ & 26.6 & $46.1 \pm 1.8$ & $27.7 \pm 0.9$ & $1.67 \pm 0.05$ \\
\hline Parade & $0.69 \pm 0.03$ & 22.9 & $51.3 \pm 2.0$ & $26.8 \pm 0.9$ & $1.91 \pm 0.04$ \\
\hline Flavortop & $0.65 \pm 0.02$ & 18.3 & $47.2 \pm 1.9$ & $23.2 \pm 0.8$ & $2.04 \pm 0.04$ \\
\hline Majestic & $0.65 \pm 0.03$ & 23.6 & $56.1 \pm 3.2$ & $28.8 \pm 1.1$ & $1.96 \pm 0.10$ \\
\hline Sunhigh & $0.57 \pm 0.03$ & 24.7 & $50.8 \pm 2.0$ & $26.9 \pm 0.7$ & $1.96 \pm 0.05$ \\
\hline Winblo & $0.56 \pm 0.03$ & 28.4 & $51.4 \pm 2.1$ & $27.5 \pm 0.6$ & $1.87 \pm 0.05$ \\
\hline Monroe & $0.54 \pm 0.04$ & 33.9 & $46.9 \pm 1.7$ & $26.9 \pm 0.7$ & $1.75 \pm 0.05$ \\
\hline O’Henry & $0.42 \pm 0.03$ & 35.2 & $45.3 \pm 1.8$ & $26.6 \pm 0.7$ & $1.71 \pm 0.05$ \\
\hline Topaz & $0.39 \pm 0.02$ & 29.5 & $46.4 \pm 1.9$ & $27.3 \pm 0.7$ & $1.69 \pm 0.05$ \\
\hline Та Таo \#6 & $0.31 \pm 0.03$ & 51.8 & $53.4 \pm 2.8$ & $33.2 \pm 1.3$ & $1.59 \pm 0.03$ \\
\hline Overall mean & 0.80 & & 50.0 & 24.5 & 1.83 \\
\hline Correlation $^{y}$ & 1.00 & & 0.14 & 0.16 & 0.02 \\
\hline
\end{tabular}

${ }^{2}$ Waller-Duncan minimum significant difference for density $=0.08$.

yearson correlation $(r)$ with density. which he rated at $0.6 \mathrm{buds} / \mathrm{cm}$ compared to 0.5 buds/cm in our test. Most of the varieties Blake tested are extinct. We only tested two varieties in common with Perez-Gonzalez (1993), 'O'Henry' and 'Redhaven', which he rated at 0.64 and 0.93 buds/node, respectively, both higher than our values of 0.42 and 0.77 . Extremes of bud density are readily observed without counting buds. 'Agua 6-4' often has three flower buds per node, in contrast to ' $\mathrm{Ta}$ Tao', which has mostly single buds per node, and many nodes with no flower buds.

Results from ANOVA show location, variety, and year main effects to be more important than any interactions in determining bud density (Table 3). The higher mean densities at Clayton than at Byron (Table 5) probably relate to growing conditions and crop load the previous year; trees at Byron were less heavily thinned, which commonly reduces return fruit bud set. Since the variety effect is much larger than any interaction, a given variety would tend to perform similarly across locations similar to ours. Although we used a fixed effects model, which limits the ability to extrapolate beyond our situation, the varieties tested represent most of the commercial peach germplasm in use in the medium-high chilling zones of the southeastern United States. In climates where peaches suffer significant midwinter bud death, spring bud counts may be misleading if the dead buds dehisce. In contrast, varieties that crop poorly in a location may have bud densities biased upwards the next spring. Mean bud density was not well correlated with shoot length, number of nodes per shoot, or internode length (Table 4). Results from ANOVA for shoot length and number of nodes (data not shown) showed year and location factors and their interaction to be highly significant and of primary importance.

In a breeding program one would want to be able to select for bud density based on single tree performance, as seedlings are rarely replicated. Variances of individual tree means (based on 10 shoots/tree) were mostly below 0.06 (detailed data not shown), which translates to an LSD $(P=0.05)$ of 0.23 buds/node. The variance of a mean using one replication; one location; 1 year; and 3, 5, or 10 shoots per tree would be $0.040,0.031$, or 0.024 , respectively. Resulting LSD values would be 0.70 , 0.31 , or 0.16 buds/node, respectively. These values would be applicable to single-budded trees of a variety, such as might be interplanted as controls, assuming seedling spacing was not so close as to interfere with bud development. Assuming cultural practices (tree density, fruit thinning) were suitable, single-tree selection among seedlings, using at least five shoots per tree, could be effective for increasing bud density. However, we did not sample seedling trees, and their flower bud development may differ from that of budded trees. Because the largest variance component was that of the error term, increasing the number of years, shoots, locations, or replications would (increasingly, in that order) reduce the variance and allow better discrimination among bud density. Clearly, it is easiest to increase the number of shoots evaluated. 
Table 5. Means \pm standard errors over years and locations for mean flower bud density (buds per node) for 25 peach and nectarine varieties.

\begin{tabular}{llcc}
\hline \hline & \multicolumn{3}{c}{ Flower bud density (no./node) } \\
\cline { 2 - 3 } Year & \multicolumn{2}{c}{ Location } & Mean over locations \\
\cline { 2 - 3 } 1988 & Byron, Ga. & Clayton, N.C. & 0.72 \\
1989 & $0.68 \pm 0.04$ & $0.75 \pm 0.03$ & 0.84 \\
1990 & $0.75 \pm 0.03$ & $0.92 \pm 0.03$ & 0.85 \\
Mean over years & $0.80 \pm 0.04$ & $0.91 \pm 0.04$ & 0.80 \\
\hline
\end{tabular}

Table 6. Stability parameter estimates ${ }^{2}$ for mean bud density of 25 peach and nectarine varieties grown in Georgia and North Carolina in 1988-90.

\begin{tabular}{|c|c|c|c|}
\hline Variety & Ecovalence & $\delta^{2}{ }_{i}$ & $\mathrm{~s}_{\mathrm{i}}^{2}$ \\
\hline Amarillo Tardio & $0.10527^{* * * *}$ & $0.08937^{* * *}$ & $0.06826^{* *}$ \\
\hline Agua 6-4 & $0.09102^{* * * *}$ & $0.07699^{* * * *}$ & $0.09623^{* * *}$ \\
\hline Bicentennial & 0.04324 & 0.03544 & $0.04370^{*}$ \\
\hline Blake & $0.10360^{* * * *}$ & $0.08792^{* * * *}$ & $0.07600^{* *}$ \\
\hline Clayton & 0.03111 & 0.02489 & 0.03110 \\
\hline Cresthaven & $0.07854^{* *}$ & $0.06614^{* *}$ & $0.05917^{* *}$ \\
\hline Eagle Beak & $0.15581^{* * * *}$ & $0.13333^{* * *}$ & $0.15001^{* * * *}$ \\
\hline Flavortop ${ }^{y}$ & 0.02209 & 0.01705 & 0.01516 \\
\hline Hardired $^{y}$ & 0.04605 & 0.03788 & 0.02953 \\
\hline Junegold & $0.06390^{* *}$ & $0.05340^{* *}$ & $0.06157^{* * *}$ \\
\hline Majestic & 0.01219 & 0.00844 & 0.00813 \\
\hline Monroe & $0.14466^{* * * *}$ & $0.12362^{* * *}$ & $0.15388^{* * * *}$ \\
\hline Norman & 0.03954 & 0.03222 & 0.03617 \\
\hline O’Henry & $0.07313^{* *}$ & $0.06143^{* *}$ & $0.07011^{* *}$ \\
\hline Parade & 0.03870 & 0.03149 & 0.03121 \\
\hline Pekin & 0.03844 & 0.03126 & 0.03643 \\
\hline Та Таo \#6 & $0.12091^{* * *}$ & $0.10298^{* * * *}$ & $0.08110^{* * * *}$ \\
\hline Redhaven & 0.04066 & 0.03320 & 0.00432 \\
\hline Redskin & 0.02421 & 0.01889 & 0.01579 \\
\hline Reliance & $0.07188^{* *}$ & $0.06034^{* *}$ & $0.06486^{* *}$ \\
\hline Sunhigh & 0.01322 & 0.00934 & 0.01154 \\
\hline Sunprince & 0.04303 & 0.03525 & $0.04323^{*}$ \\
\hline Surecrop & 0.02507 & 0.01964 & 0.01618 \\
\hline Topaz & 0.01856 & 0.01398 & 0.01707 \\
\hline Winblo & $0.04715^{*}$ & $0.03884^{*}$ & $0.04495^{*}$ \\
\hline
\end{tabular}

${ }^{2}$ Ecovalence stability index (wi) (Kang, 1989); stability variance $\left(\delta^{2}\right)$ and adjusted stability variance $\left(\mathrm{s}_{\mathrm{i}}^{2}\right)$ (Shukla, 1972).

${ }^{\mathrm{y}}$ Nectarine.

${ }^{*, * * * * * * *}$ Significant at $P=0.05,0.01$, or 0.001 , respectively.

When shoot variation is removed by using means for trees, the ANOVA $R^{2}$ value for bud density based on location, year, and variety effects is very high (0.93). Calculations of variance components show that variety effects nificant estimates would be more stable (Table 6), those with the most highly significant values are less stable. The same varieties are shown as unstable by all three parameters. Although this instability reflects nontypical performance across environments, the relative ranking was similar in most cases. Broad sense heritability was calculated as $100 \times$ $0.0935 / 0.2009=47 \%$. This value indicates selection for high bud density would be effective. Selection would also be effective for low bud density, which would allow development of varieties for areas without spring frost, to reduce thinning costs.

\section{Literature Cited}

Blake, M.A. 1933a. Classification of 135 varieties and species of peaches and nectarines on basis of fruit bud set at New Brunswick. N.J. Agr. Expt. Circ. 274.

Blake, M.A. 1933b. New Jersey standards for classifying the set of fruit buds upon peaches. N.J. Agr. Expt. Circ. 271.

Fernandez, G.C.J. 1991. Analysis of genotype $\times$ environment interaction by stability estimates. HortScience 26:947-950.

Jones, G.L., D.F. Matzinger, and W.K. Collins. 1960. A comparison of flue-cured tobacco varieties repeated over locations and years with implications on optimum plot size. Agron. J. 52:195-199.

Kang, M.S. 1989. A new SAS program for calculating stability-variance parameters. J. Hered. 80:415.

Perez-Gonzalez, S. 1993. Bud distribution and yield potential in peach. Fruit Var. J. 47:18-25.

SAS Institute. 1987. SAS/STAT guide for personal computers, version 6 edition. SAS Inst., Cary, N.C.

Schultz, E.F., Jr. 1955. Rules of thumb for determining expectations of mean squares in analysis of variance. Biometrics 11:123-135.

Shukla, G.K. 1972. Some statistical aspects of partitioning genotype-environmental components of variability. Heredity 29:237-245.

Werner, D.J., B.D. Mowrey, and J.X. Chaparro. 1988. Variability in flower bud number among peach and nectarine clones. HortScience $23: 578-580$ 